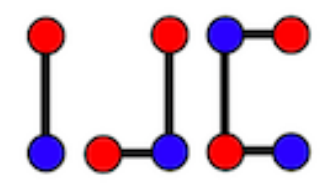

\title{
On super $(a, d)$-edge antimagic total labeling of branched-prism graph
}

\author{
Khairannisa Al Azizu, Lyra Yulianti ${ }^{1}$, Narwen, Syafrizal Sy \\ Department of Mathematics, \\ Faculty of Mathematics and Science, Andalas University, \\ Kampus UNAND Limau Manis Padang, Indonesia
}

khairannisa10@gmail.com, lyra@sci.unand.ac.id, narwen@sci.unand.ac.id, syafrizalsy@sci.unand.ac.id

\begin{abstract}
Let $H$ be a branched-prism graph, denoted by $H=\left(C_{m} \times P_{2}\right) \odot \bar{K}_{n}$ for odd $m, m \geq 3$ and $n \geq 1$. This paper considers about the existence of the super $(a, d)$-edge antimagic total labeling of $H$ for some positive integer $a$ and some non-negative integer $d$.
\end{abstract}

Keywords: Super $(a, d)$-edge antimagic total labeling, branched-prism graph

Mathematics Subject Classification: 05C12, 05C15

DOI: $10.19184 /$ ijc.2021.5.1.2

\section{Introduction}

In [5], Hartsfield and Ringel gave the concept of antimagic labeling of a graph. Let $G$ be an arbitrary graph $G$ on $p$ vertices and $q$ edges. Graph $G$ is called antimagic if its edges are labeled with $1,2, \cdots, q$ such that all the vertex weights are pairwise distinct. Next, for some integers $a>0$ and $d \geq 0$, Bodendick and Walther [3] introduced the concept of $(a, d)$-antimagic labeling as an edge labeling such that the vertex weights form an arithmetic progression starting from $a$ and having a common difference $d$. Moreover, Simanjuntak et al. [6] defined an $(a, d)$-edge antimagic vertex labeling of $G$ as a mapping $f: V(G) \rightarrow\{1,2, \cdots, p\}$ such that the set of edge weights $W_{1}=\{f(u)+f(v) \mid u v \in E(G)\}$ can be written as $\{a, a+d, a+2 d, \cdots, a+(q-1) d\}$, for some non-negative integers $a$ and $d$. A mapping $g: V(G) \cup E(G) \rightarrow\{1,2, \cdots, p+q\}$ such that

\footnotetext{
${ }^{1}$ corresponding author

Received: 10 January 2020, Revised: 13 December 2020, Accepted: 10 February 2021.
} 
the set of edge weights $W_{2}=\{g(u)+g(v)+g(u v) \mid u v \in E(G)\}$ form an arithmetic progression $\{a, a+d, a+2 d, \cdots, a+(q-1) d\}$, for $a>0$ and $d \geq 0$, is called an $(a, d)$-edge antimagic total labeling of $G$. If $d=0$ then the $(a, 0)$-antimagic labeling becomes the magic labeling with magic constant $a$. Some previous results on magic and antimagic labeling are listed in a book by Baca and Miller [2] and also in an updated survey by Gallian [4].

Sugeng et al. [7] determined the super $(a, d)$-edge antimagic total labeling (super $(a, d)$ EAMTL) of a generalized prism graph $C_{m} \times P_{r}$ for $m \geq 3$ and $r \geq 2$. In [1], Azizu et al. defined the branched-prism graph, denoted by $H=\left(C_{m} \times P_{2}\right) \odot \bar{K}_{n}$, for $m \geq 3$ and $n \geq 1$, where $\bar{K}_{n}$ denotes the complement of a complete graph on $n$ vertices. They also determined the existence of a super edge magic labeling (super EMTL) of the branched-prism graph. In this paper, it will be shown that $H$ admits a super $(a, d)$-edge antimagic total labeling for odd $m, m \geq 3$ and $n \geq 1$.

\section{The Branched-Prism Graph and Its Super $(a, d)$-Edge Antimagic Labeling}

Azizu et al. [1] gave the definition of branched-prism graph as follows. The graph is constructed from the corona operation between prism graph $C_{m} \times P_{2}$ and the complement of a complete graph $\bar{K}_{n}$ on $n$ vertices, denoted by $H=\left(C_{m} \times P_{2}\right) \odot \bar{K}_{n}$, for $m \geq 3$ and $n \geq 1$. The vertex set and edge set of $H$ are defined as follows.

$$
\begin{aligned}
V(H)= & \left\{v_{i, j}, v_{i, j, k} \mid 1 \leq i \leq 2,1 \leq j \leq m, 1 \leq j \leq n\right\}, \\
E(H)= & \left\{v_{i, j} v_{i, j+1} \mid 1 \leq i \leq 2,1 \leq j \leq m-1\right\} \cup\left\{v_{i, m} v_{i, 1} \mid 1 \leq i \leq 2\right\}, \\
& \cup\left\{v_{1, j} v_{2, j} \mid 1 \leq j \leq m-1\right\} \cup\left\{v_{1, m} v_{2, m}\right\} \\
& \cup\left\{v_{i, j} v_{i, j, k}, v_{i, m} v_{i, m, k} \mid 1 \leq i \leq 2,1 \leq j \leq m-1,1 \leq k \leq n\right\} .
\end{aligned}
$$

It is clear that $H$ has $p=2 m n+2 m$ vertices and $q=2 m n+3 m$ edges. Graph $H$ is given in Figure 1.

The following theorem gives the upperbound of the difference $d$ in the super $(a, d)$-EAMTL of $H$.

Theorem 2.1. Let $H=\left(C_{m} \times P_{2}\right) \odot \overline{K_{n}}$ be the branched-prism graph on $2 m n+2 m$ vertices and $2 m n+3 m$ edges. If $H$ admits the super $(a, d)$-edge antimagic total labeling then $d \leq 2$.

Proof. Suppose that $H$ has a super $(a, d)$-EAMTL, defined by $f: V(H) \cup E(H) \rightarrow\{1,2, \cdots, 4 m n+$ $5 m\}$. The set of edge weight can be written as $\{a, a+d, \cdots, a+(q-1) d\}$, where $q=2 m n+3 m$. The minimum possible edge-weight of this labeling is $1+2+(2 m n+2 m+1)=2 m n+2 m+4$, and the maximum possible edge-weight is $(2 m n+2 m-1)+(2 m n+2 m)+((2 m n+2 m)+$ $(2 m n+3 m))=3(2 m n+2 m)+(2 m n+3 m)-1=8 m n+9 m-1$. Therefore,

$$
\begin{aligned}
a & \geq 2 m n+2 m+4 \\
a+(q-1) d=a+(2 m n+3 m-1) d & \leq 8 m n+9 m-1 .
\end{aligned}
$$




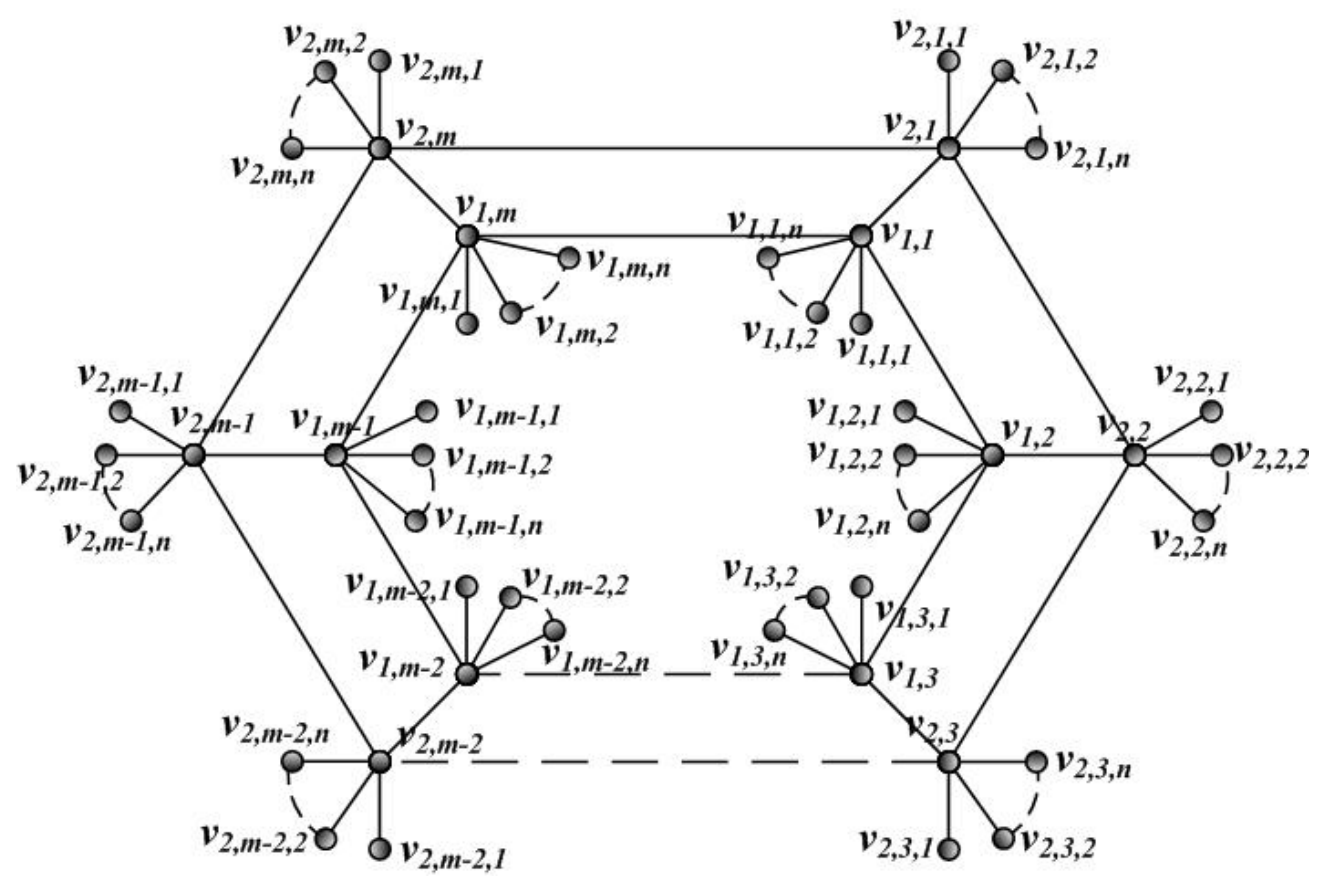

Figure 1. [1] The branched-prism graph $H=\left(C_{m} \times P_{2}\right) \odot \overline{K_{n}}$

From (1) and (2), we have the following inequality:

$$
\begin{aligned}
2 m n+2 m+4+(2 m n+3 m-1) d & \leq 8 m n+9 m-1 \\
d & \leq \frac{8 m n+9 m-1-(2 m n+2 m+4)}{2 m n+3 m-1} \\
& =\frac{6 m n+7 m-5}{2 m n+3 m-1} .
\end{aligned}
$$

For $m \geq 3$ and $n \geq 1$, it is clear that $d<3$. Therefore, if $H$ admits the super $(a, d)$-EAMTL then $d \in\{0,1,2\}$.

The following theorem gives the super $(a, d)$-EAMTL of $H$ for $d=1$ and $d=2$. The super $(a, 0)$-EAMTL of $H$, or the super EMTL of $H$, has been obtained in [1].

Theorem 2.2. Let $H=\left(C_{m} \times P_{2}\right) \odot \overline{K_{n}}$ be the branched-prism graph on $2 m n+2 m$ vertices and $2 m n+3 m$ edges. For odd $m, m \geq 3$ and $n \geq 1$, there exist a super $\left(a_{1}, 1\right)$-edge antimagic total labeling and $a$ super $\left(a_{2}, 2\right)$-edge antimagic total labeling of $H$, where $a_{1}=4 m n+4 m+2$ and $a_{2}=3 m n+2 m+\frac{(m+1)}{2}+2$.

Proof. Let $H=\left(C_{m} \times P_{2}\right) \odot \overline{K_{n}}$ be the branched-prism graph on $2 m n+2 m$ vertices and $2 m n+3 m$ edges, for odd $m, m \geq 3$ and $n \geq 1$. First, define the vertex labeling $f: V(H) \rightarrow$ 
$\{1,2, \cdots, 2 m n+2 m\}$ as follows.

$$
\begin{aligned}
& f\left(v_{1, i, j}\right)=\left\{\begin{array}{l}
\frac{i+1}{2}+m(j-1), \quad \text { for odd } i, 1 \leq i \leq m, 1 \leq j \leq n, \\
\frac{m+i+1}{2}+m(j-1), \quad \text { for even } i, 2 \leq i \leq m-1,1 \leq j \leq n .
\end{array}\right. \\
& f\left(v_{1, i}\right)=\left\{\begin{array}{l}
m n+\frac{i}{2}, \quad \text { for even } i, 2 \leq i \leq m-1, \\
m n+\frac{m+i}{2}, \quad \text { for odd } i, 1 \leq i \leq m .
\end{array}\right. \\
& f\left(v_{2, i}\right)=\left\{\begin{array}{l}
m n+2 m, \quad \text { for } i=1, \\
m n+m+\frac{i-1}{2}, \quad \text { for odd } i, 3 \leq i \leq m, \\
m n+m+\frac{m+i-1}{2}, \quad \text { for even } i, 2 \leq i \leq m-1 .
\end{array}\right. \\
& f\left(v_{2, i, j}\right)=\left\{\begin{array}{l}
m n+2 m+\frac{m-1}{2}+m(j-1), \quad \text { for } i=1,1 \leq j \leq n, \\
m n+3 m+m(j-1), \quad \text { for even } i, 4 \leq i \leq m-1,1 \leq j \leq n, \\
m n+2 m+\frac{i-2}{2}+m(j-1), \quad \text { for odd } i, 3 \leq i \leq m, 1 \leq j \leq n .
\end{array}\right.
\end{aligned}
$$

Denote $S=\{f(x)+f(y) \mid x y \in E(H)\}$ as the set of edge weights of the vertex labeling of $H$. Therefore, $S=\left\{m n+1+\frac{(m+1)}{2}, m n+\frac{(m+1)}{2}+2, \cdots, 3 m n+3 m+\frac{(m+1)}{2}-1,3 m n+3 m+\frac{(m+1)}{2}\right\}$.

Next, define the edge labeling $f: E(H) \rightarrow\{2 m n+2 m+1,2 m n+2 m+2, \cdots, 4 m n+5 m\}$ as follows. The set of edge weights of the total labeling is denoted by $W=\{f(x)+f(y)+f(x y) \mid$ $x y \in E(H)\}$. It can be seen that $W=\{s+f(x y) \mid x y \in E(H), s \in S\}$. Consider the following cases.

Case 1. $d=2$.

Define the minimum edge weight as

$$
\begin{aligned}
a & =\min \{f(x y) \mid x y \in E(H)\}+\min \{s \mid s \in S\} \\
& =(2 m n+2 m+1)+\left(m n+1+\frac{(m+1)}{2}\right) \\
& =3 m n+2 m+\frac{(m+1)}{2}+2 .
\end{aligned}
$$

By choosing this minimum value of edge weight, we have the difference $d=2$.

Case 2. $d=1$.

Let $s \in S$. Define the edge labeling of $H$ as follows.

$$
f(x y)= \begin{cases}s, & \text { for } 2 m n+2 m+1 \leq s \leq 3 m n+3 m+\frac{m+1}{2}, \\ 2 m n+3 m+s, & \text { for } m n+1+\frac{m+1}{2} \leq s \leq 2 m n+2 m .\end{cases}
$$


By defining this edge labeling, the minimum edge-weight is

$$
a=s+f(x y)=(2 m n+2 m+1)+(2 m n+2 m+1)=4 m n+4 m+2 .
$$

Therefore, there exist a super $\left(a_{1}, 1\right)$-EAMTL and a super $\left(a_{2}, 2\right)$-EAMTL of $H$, where $a_{1}=$ $4 m n+4 m+2$ and $a_{2}=3 m n+2 m+\frac{(m+1)}{2}+2$.

In Figure 2 we give a super $(75,2)$-EAMTL of $\left(C_{5} \times P_{2}\right) \odot \overline{K_{4}}$. The red labels are for the vertices, while the blue ones are for the edges.

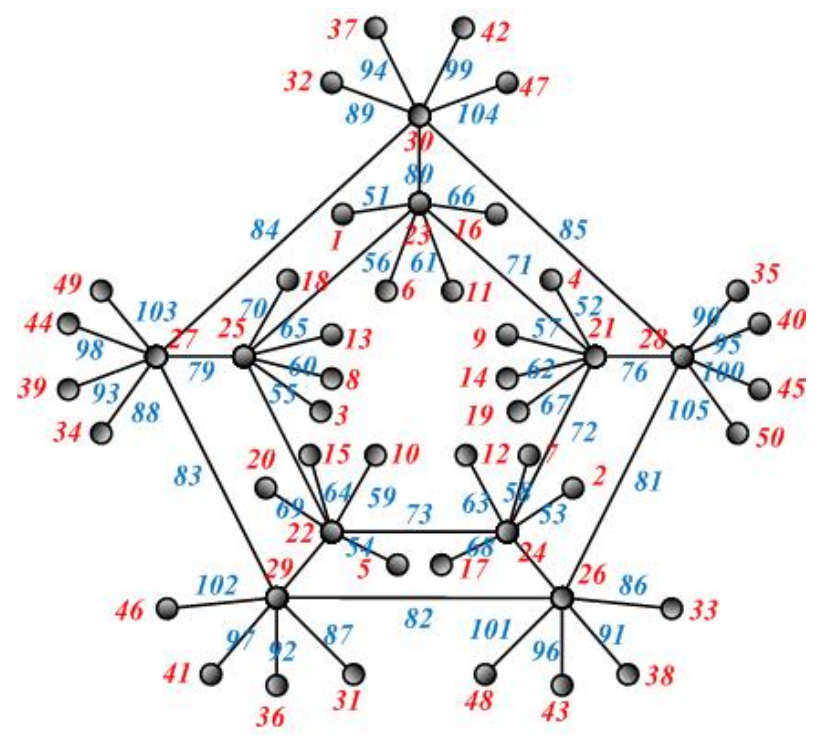

Figure 2. A Super $(75,2)$-EAMTL of $\left(C_{5} \times P_{2}\right) \odot \overline{K_{4}}$

\section{Conclusion}

This paper shows that the branched-prism graph $H=\left(C_{m} \times P_{2}\right) \odot \overline{K_{n}}$ admits a super $(4 m n+$ $4 m+2,1)$-EAMTL and $\left(3 m n+2 m+\frac{(m+1)}{2}+2,2\right)$-EAMTL for odd $m, m \geq 3, n \geq 1$. Combining this result with [1], we have the super $(a, d)$-EAMTL of the branched-prism graph for $d \in\{0,1,2\}$.

\section{References}

[1] K.A. Azizu, L. Yulianti, S. Sy, N. Narwen, On super edge magic total labeling of the branched-prism graph. International Journal of Progressive Sciences and Technologies 16 (2) (2019), $203-206$.

[2] M. Baca, M. Miller, Super Edge-Antimagic Graphs: A Wealth of Problems and Some Solutions. Brown Walker Press (2008). 
[3] R. Bodendiek, G. Walther, Arithmetisch Antimagische Graphen. In: K. Wagner and R. Bodendiek, eds. Graphentheorie III, BI-Wiss Verl., Mannheim (1993).

[4] J. A. Gallian, A Dynamic survey of graph labeling. Electron. J. Combin. (2020), \#DS6.

[5] N. Hartsfield, G. Ringel, Pearls in Graph Theory. Academic Press. Boston (1990).

[6] R. Simanjuntak, M. Miller, F. Bertault, Two new $(a, d)$-antimagic graph labeling. Proc. of the Eleventh Australasian Workshop on Combinatorial Algorithms, (2000), 179 - 189.

[7] K.A. Sugeng, Super edge antimagic total labeling. Util. Math. 71 (2006), 131 - 141.

[8] W.D. Wallis, Magic Graphs. Birkhauser, Boston (2001). 